\title{
Economics of knowledge and the governance of commons knowledge'
}

\author{
Cristiano Antonelli
}

Laboratorio di Economia dell'innovazione D ipartimento di Economia Universitá di Torino

\section{ABSTRACT}

Economics of knowledge provides new tools to study the features of knowledge as an economic good and new waysto understanding the governance of knowledge. This sheds new light upon theinstitutional design, theincentives mechanisms, including intellectual property rights, and the signalling devices that makeit possibletheorganization of the production and distribution of knowledgein economic systems.

KEYWORDS | economics of knowledge/ appropriability-indivisibility-cumulability-fungibilitycomplexity/interactions-transactions/externalities-spillovers/ intellectual property rights.

\section{JEL-CODES $\mid$ L2, 03}

\footnotetext{
1 The funding of the research project "Technological Knowledge and Localised Learning: What Perspectives for a European Policy?" carried on under the research contract No. HPSE-CT2001-00051 of the European Directorate for Research within the context of the Key Action "Improving the socio-economic knowledge base" it is acknowledged, as well as the remarks of Aldo Geuna and Pier Paolo Patrucco to preliminary versions of this paper, the comments of Jean Luc Gaffard and Michel Quéré after its presentation at the IDEFI workshop "Innovation and growth: New challenges for the regions" at Sophia-Antipolis, 18-20 January 2002.
} 


\section{Resumo}

A economia do conhecimento oferecenovos instrumentos para o estudo de suas características como um bem econômico enovas formas deentendimento da governança do conhecimento. I sto lança novas luzes sobre o desenho institucional, os mecanismos de incentivo, incluindo a propriedade intelectual, e os dispositivos sinalizadores que tornam possível a organização da produção e distribuição do conhecimento em sistemas econômicos.

Palavras-chave | Economia do Conhecimento/ apropriabilidade-indivisibilidadecumulatividade complexidade/ interaçõestransações/ externalidades-transbordamentos/ direitos depropriedadeintelectual.

CÓdIGOJEL | L2,03

\section{Introduction}

Important shifts in the economics of knowledge have occurred in recent years. Consensus on the analysis of the public good characters of knowledge has been first contrasted and eventually substituted by thenew argument about the quasi-private nature of technological knowledge. The appreciation of demand-side externalities and external knowledge at large has called for a new interest upon the mechanisms of governance upon which the production and the distribution of knowledge builds upon. The understanding of multiple equilibria and micro-macro feedbacks calls back attention to the crucial role of the economic policy. This had important consequences on the institutional design for the organization of the production and distribution of knowledge.

This process can be summarized in three stages. The first recalls the ingredients of the great swing from the build-up of the public knowledge commons to the wave of privatizations and liberal ization. The identification of the central role of external knowledgein the production of new knowledge marks the second step, where the discovery of a knowledge trade-off stresses the role of the governance in all interactions and exchanges for knowledge. The understanding of theinstability of market interactions, in the production 
and distribution of technological knowledge, should pave the way to the third step, where is identified a new scope for an economic policy able to manage dynamic coordination issues.

\section{The great swing}

The seminal contributions of K enneth Arrow and Richard N elson had long shaped the debate about the economic organization for the supply of knowledge. In their approach technological knowledge was seen as a public good for the high levels of indivisibility, non-excludability non-tradability and hencenon-appropriability. In this context markets are not ableto provide the appropriate levels of knowledge because of both the lack of incentives, and the opportunities for implementing the division of labor and hence achieving adequate levels of specialization. The public provision of technological knowledge, and especially scientific knowledge has been long regarded as the basic remedy to under-provision.

The public provision of scientific and technological knowledge by means of thefunding to Universitiesand other public research bodies, as well as directly to companieswilling to undertakeresearch programs of general interest, found in this argument a rationale. This lead to the actual build-up and the systematic implementation of public common knowledge (Swann, 2002).

The new approach marked a major divide. In pre-Arrowian times in fact ex-ante monopolistic market power had been advocated as the proper tool to foster the rate of accumulation of technological knowledge and hence of introduction of technological change. Barriers to entry in existing product markets securethefinancial resourcesto fund research and development expendituresand, most importantly, reduce the risks of uncontrolled leakage and imitation. Competitors haveyet to enter and entry is barred by substantial cost disadvantages. In this model, innovations are necessarily embodied in new companies. The competitive advantage of innovating companies provides, at the same time, a measure of the quality of the innovation and an incentive to its introduction. The circulation of innovations was assured by the imitation of competitors.

The arrovian approach impinged upon a second leg. The creation of intel lectual property rights was in fact regarded originally as a complementary 
institutional set-up, parallel to the public provision of scientific knowledge. Patents and copy-rights, if properly implemented, can reducenon-excludability and non-appropriability. In a proper institutional design, intellectual property rights may also favour tradability and hence lead to higher levels of specialization and division of labour. Intellectual property rights can help increasing the incentives to the production of scientific and technological knowledge (Alchian and D emsetz, 1973).

The build-up of an economics of intellectual property rightshashowever eventually articulated thestronger hypothesis that appropriate implementation of patents, finely tuned in terms of scope, duration and assignment procedures, can reduce or even erase the problems raised by the public good character of technological knowledge. At the same time much empirical evidence and theoretical research has shown that appropriability is de facto much higher than assumed. Knowledge is contextual and specific to the original conditions of accumulation and generation: as such natural appropriability conditions are far better than assumed. I mitation costs seem high as well as the costs of receptivity and re-engineering necessary to make use of non-proprietary knowledge. The costs of the non-invented-here-syndrome are appreciated. The assistance of original knowledge holders to perspective users is relevant, if not necessary.

These two strands of analysis, ex-post, contributed with complementary arguments to the new hypothesis that the supply and the demand for technological knowledge can be identified, the actual creation and implementation of markets for technological knowledge is possible and the results of such market interactions are compatible with a workable competitive system in the proximity of equilibrium conditions.

This new approach leads not only to endogenous growth theorizing but also to significant steps towards the privatization of public knowledge. Universities were solicited to patent their discoveries and often forced to enter the markets for the technological outsourcing of large corporations. Public funding to research activities declined and was questioned if not put under strain. A closer look to the working of the public commons and the actual need to put under scrutiny the productivity of the resources invested in the public knowledge commons, both at the system and the single units level, 
was advocated. Some attempts to liberalize the markets were also made, especially in the new general purpose technology field of new information and communication technologies with the divestiture in telecommunications and a new and more aggressive antitrust stance (D avid, 1997).

\section{The discovery of external knowledge and the knowledge trade-off}

The analysis of appropriability made it possible to the economics of innovation to understand the key role of technological externalities and the positive effects of technological spill-overs. The discovery of external knowledge, available not only by means of transactions in the markets for knowledge, but also by means of technological interactions, marks a new important step in the debate. External knowledge is an important input in the production process of new knowledge. The appreciation of external knowledge, as an essential input in the production of new knowledge, was later articulated in the systems of innovation approach, where the production of knowledge is viewed as the result of the cooperative behavior of agents undertaking complementary research activities (Antonelli, 2001).

The costs of exclusion associated to intellectual property rights, as a consequence, should betaken into account. M onopolistic control of relevant bits of knowledge, provided both ex-ante and ex-post by patents and barriers to entry in the products markets respectively, can prevent not only its uncontrolled leakage and hence its dissemination but also further recombination, at least for a relevant stretch of time.

The advantages of the intellectual property right regime, in terms of increased incentives to the market provision of technological knowledge are now balanced by the costs in terms of delayed usage and incremental enrichment. The vertical and horizontal effects of indivisibility display their powerful effects in terms of cummulability. Indivisibility of knowledge translates into the basic cumulative complementarity among bits of knowledge. Complementarity and cumulability in turn imply that new bits of knowledge can be better introduced building upon other bits already acquired, both in the same specific context and in other adjacent ones. The 
access exclusion from the knowledge al ready acquired reduces the prospect for new acquisitions and in any event hasa strong social cost in terms of duplication expenses.

$\mathrm{H}$ ere in the economics of technological knowledge the issues of externalities in the demand side become relevant and evident. Thegeneration of technological knowledge is now considered to be characterized by demand externalities. Thenotion of user-interdependencemakes itsforay into thescene when agents valuethe levels of usage of other agents of certain goods. Asfar as scientific and technological knowledge is concerned, interdependence among users, hence in the demand side, is in fact very strong. The actual chances of generating a new relevant bit of knowledge for each agent depend upon the levels of accumulation of skills and competence, education and access to information of the other agents in the community.

The amount of external technological knowledge, available in a given context, industrial, technological or regional, becomesan important endowment, as well as the conditions of access to it and the characteristics of the relational set-up. A variety of players contributes the amount of external technological knowledge: firms, universities and research centres, as well as brokers and other undertakings specialized in the spread of technological knowledge such as knowledgeintensivebusiness serviceactivities. Theinstitution sof labour markets play an important role: job-seniority and wagestructures can modify theflows of technological knowledge especially in a regional context (Cooper, 2001). Interindustrial division of labour and outsourcing in general also play an important role as they increase the flows of technological communication. Knowledge-intensive business service activities emerge as providers of technological knowledge and complementary actorsin the trade of patents and other intellectual property rights.

Theissues of the distribution of knowledgebecome central in the debate and the notion of an actual knowledge trade-off is articulated. Uncontrolled leakage and low appropriability regimes reduce incentives and lead to underprovision. Excess appropriability, both ex-anteand ex-post, however may slow down if not impedetheworking of knowledge complementarity, cumulability and fungibility. A governance of the knowledge trade-off is necessary both at the firm and at the system levels (M azzoleni and N elson, 1998). 


\section{The governance of the generation and usage of technological knowledge}

The analysis of the governance of both the generation and usage of technological knowledge and that of the mechanisms designed and of the conditions of access and exclusion to the flows of technological interactions, transactions, coordination and communication that are specifically designed to handlethe generation and the distribution of technological knowledge deserves a careful assessment and scrutiny (M enard, 2000; C arroll and Teece, 1999; W illiamson, 1985 and 1996; Langlois, 1986).

Inclusion needs to be coordinated and managed. Free riding can take place, although reciprocity and mutuality in interactions based upon knowledge barters, implemented by repeated and long-lasting exchanges, can help reducing the extent and the effect. Exclusion is dangerous for the risks of missing the relevant complementary input which characterizes the generation of new technologies (Swann, 2002).

In this context the company is the primary actor. The company is viewed as the locus where technological and organizational knowledge is generated by means of theintegration of learning processes and formal research and development activities. The company it isconsidered in this approach primarily as a depository and a generator of competence. Such competence applies to the manufacturing processes as well as to the management of the internal coordination and to the procedures and the skills that are necessary to use the markets (Foss, 1997).

The resource-based theory of the company has grown as a development and an application of theeconomics of learning. Theenquiry about thedynamics and the characteristics of learning processes, such as learning by doing and learning by using, and their relevancein explaining technological change hasled to the identification of thefirm as the primary locus of the generation and valorization of knowledge immediately relevant for the economic action, at least in market economies (Loasby, 1999).

The resource-based theory of the company focuses theattention on the characteristics of the process of accumulation of competence, the generation of technological knowledge and the introduction of technological and organizational innovations, as key factors to understanding the firm. The 
characteristics of knowledge, such as appropriability, cumulability and complementarity, and its state whether tacit, articulable or codified, play a major role to understand the architectural design of the company and the combination of activities retained within its borders. Parallel to knowledge, competence is a central ingredient in theresource-based theory of the company. Competence is defined in terms of problem-solving capabilities and makes it possible for the company not only to know-how, but also to know-where, to know-when, and to know what to produce, to sell, to buy, to coordinate and to innovate (N ooteboom, 2000).

The company itself is more and more regarded as an island of coordination procedures that facilitate the accumulation of knowledge. The Coase-W illiamson argument, much applied to the choice between coordination and transaction in the organization of the economic activity, can now be stretched and elaborated so as to understanding the fabric of technological knowledge (Furubotn, 2001).

W ithin corporations the coordination of technological communication becomes a relevant issue. The organization of companies appears to be influenced also by the need to implement and value the complementarity of the bits of knowledge possessed and accumulated in the diverse units. The distinctive notion of the costs of technological transactions and interactions can also be identified. The trade-off between knowledge coordination costs and knowledgetransaction and interaction costs contributes the understanding of the technological choices of the company (Argyres, 1995).

In the governance of knowledge not only the traditional 'make or buy' trade-off is relevant, but al so a 'make or sell' choice has to be considered. The company, in fact, needs to assess not only whether to rely upon external or internal knowledge in the production of new knowledge, but also whether to try and value the knowledge available internally as a good itself and sell it disembodied in the markets for technological knowledge, or to use it as an input in the production of other goods.

A wide range of choices in terms of governance can be analyzed and understood also with respect to thecharacteristics of the processes of knowledge generation and usage. Technological strategies can be implemented by means of internal research and development laboratories, technological outsourcing, 
location of research and development centres in technological districts, technological alliances and research joint-ventures and finally actual mergers and acquisition (Antonelli and Q uéré, 2002).

Theeconomics of technological knowledgehasmade important progress in the identification of specific characteristics of technological knowledge. The forms and the types of knowledge matter. D ifferent governance mechanisms and governance choices emerge according to the characteristics of technological knowledge.

The forms of the relevant technological knowledge matter: whether technological is more tacit, articulable or codified has a direct bearing on the governance of the accumulation process. The exchange of tacit scientific and technological knowledge seems easier within research communities based upon repeated interactions and closed reciprocity in communication. Random inclusion can take place with positive effects, provided newcomers are properly selected (C owan and J onard, 2002).

Theincentives to the creation of informal interaction procedures, often implemented by co-localization within technological districts, are very strong in this case. Collective bodies such as industrial clusters emerge as important governance structures especially when technological knowledge is tacit and articulation requires complex procedures.

The exchanges and interactions in articulable knowledge take better place within technological clubs and coalitions where membership is closely assessed and selectivity requirements are far higher. The reputation of the fellows in the club playsan important rolein building closed research coalitions (Teece, 2000). When technological knowledge is more articulable, the contractual interaction among partners within research joint-ventures and technological clubs can be better implemented. The distinction between procedural and content contracts is relevant here. Procedural contracts are designed to specify the modality of the interaction while content contract focus the characteristics of theactual transaction. Specific procedural contracts about the process of participation and timing of assignment of property rights, temporary and partial exclusivity, time lags and partial domains of privilege to relevant contributors, depending on both the amount of inputs and the actual results, can be designed and possibly enforced. 
In this context theinteractionsand the transactions between the business and the academic communities seem to find their specific context of implementation. T heinterface between tacit and codified knowledge, defined as articulableknowledge, provides in fact the opportunity to definethe points of common interest between the two parties while the broader goals of the scientific undertaking in terms of the commitments towards the creation of intellectual commons can still be pursued.

Codified technological knowledge better meets the conditions for tradability especially if implemented by an appropriate intellectual property right regime and when the assistance of inventors and as such vendors to perspective users is necessary and useful to reduce adoption and adaptation costs. The markets for technological knowledge with actual transactions are often found in this context. The design of actual content contracts, such asin the case of licences, is possible and enforcement more reliable.

$\mathrm{N}$ ext to the forms of the technological knowledge, its types play an important role. The complexity, fungibility, cumulability and tradability of technological knowledge in assessing the governance mode of the generation and usage of new technological knowledge can be fully appreciated.

The fungibility of the technological knowledge generated by each company, especially if associated with high levels of cumulability, provides important incentives towards internalization and hence diversification. Diversification and multinational growth can be seen as strategic choices elaborated by companies in order to value intangi ble assets which cannot be traded as such in the markets for disembodied knowledge. G rowth thus is a tool used to value intangible assets, which cannot be appropriated by means of intellectual property rights, but only when embodied in traditional property rights. Thefirm has in fact the opportunity to appropriate the rents stemming from the application of its knowledge in the productions of previously unrelated goods. Q ualified user-producer interactions are also useful when the application of fungibility requires the active involvement of downstream or upstream actors.

Diversification can be the consequence of the generation of new knowledge, as well as a tool, hence a factor, in the knowledge generation process. External growth can be guided by the search for complementary 
competencies. Those that play a strategic role to make technological innovations possible.

Thelarger the complexity of the technological knowledge necessary to generate new technologies the more likely the implementation of strategies based upon technological outsourcing. When the technological base of a company is complex and requires the integration and recombination of a large variety of technological domains, the use of external knowledge is encouraged by the high levels of internal coordination costs of the diverse sources and competencies that are necessary.

Technological outsourcing can takeplacein many different ways. External knowledgecan beaccessed by means of actual transactions of patents and licences, the purchase of research and knowledge servicesfrom knowledgeintensivebusiness services firms including universities and other research centers, the location in knowledge intensive districts and finally the acquisition of knowledge intensive companies. Financial markets can be seen as markets for knowledge where technological knowledge is no longer embodied in capital goods, intermediary inputs or skills, but directly into financial assets. The acquisition of a company can bean effectiveform of accessing external knowledge.

Conversely, thelarger is the cumulability of the technological knowledge specific to the products and the production process of a company, thelarger are the incentives towards the internalization of the knowledge generation process. Technological outsourcing in fact has high costs in terms of missed opportunities for further advances. The sameargument applies when learning plays a key role in the generation of new knowledge: the full control of the production process is likely to yield important benefits in terms of increased rates of accumulation of new technological knowledge.

The understanding of the governance of technological knowledge and of the demand side externalities in technological knowledge makes possible important contributions to the economics of governance. Governance structures not only depend upon the characters of the transactions and of the production processes for given technologies and within the boundaries of the existing technological base. Governancestructuresareinfluenced by theroleand the features of technological knowledge. The governance of the generation and usage of technological knowledgeemergesas an important area for empirical and 
theoretical investigation. The governance of the knowledge trade-off has many important implications not only at the company level, but also with respect to the system at large. (Teece, 2000; N elson and Sampat, 2001).

The notion of knowledge fungibility plays an important role in this context. It seems clear that the larger is the fungibility the wider is the scope of application and recombination of any specific bits of knowledge and the larger the costs of exclusion. G eneral purpose technologies should be more accessiblethan specific single usage technologies. Theassignment of intellectual property rights should be tuned, according to the social costs of exclusion from specific portions of technological knowledge, according to their scope of application and to their relevance with respect to further discoveries. The definition of the domains of cumulability becomes most relevant. M odularity seems pertinent also in this context. Chains of weak and strong complementarity and cumulability can be detected and modules of technological knowledge can be identified. The effects of utility interdependence can be mapped into well-defined regions with borders designed by theactual extent of knowledge complementarity and cumulability (Antonelli, 2001).

The identification of such modules in turn becomes relevant from a strategic point of view at the company level. Some companies, that are a depository of some bits of knowledge, are likely to be more interdependent than others with some subclasses of other agents. The externalities spilling from their own research agenda and their own acumulated competence can be more relevant than others'. The identification of technological modules and the drawing of specific knowledge maps into which each agent is placed can becomea tool to activate the innovation capability of both the company and the system with proper policy strategies.

The understanding of the actual levels of cumulability, fungibility and complementarity of well identified modules of technological knowledgeboth on the usage and supply side, moreover makes it possible to grasp, especially at the aggregate level, the dynamics of increasing returns. The larger is the number of agents which hold relevant portions of knowledge that are complementary and the larger is the output in terms of technological knowledge and eventually the weal th a system can generate. Externalities are 
directly the engine of increasing returns. In turn such increasing returns can be circumscribed within the boundaries of the knowledge modules.

This approach paves the way to a radical shift in the debate about intellectual property rights. Intellectual property rights are now viewed as necessary signalling devices. W ithout intellectual property rights and specifically without patents, the companies would rely upon secrecy in order to increase appropriability. $\mathrm{H}$ igher levels of secrecy in turn would make it more difficult to identify the relevant bits of knowledge and to activate the interactions, which amplify technological externalities.

Theinformational role of patents as carriers of relevant information about the availability of new bits of knowledge is now more and more appreciated. The identification of each bit of complementary and useful knowledgeas well as of the agents holding specific bits of knowledge and the assessment of their complementarity becomesan important function. Thisis expensiveboth in terms of search and opportunity costs: the costs of interacting with the wrong agentsin terms of low opportunities. A specific form of knowledgetransaction cost can be identified here. Theselection of the companiesand agentswith whom technological cooperation and technological communication can takeplaceisa relevant aspect of the governance mechanism and of the governance process. On which the creation of technological clubs and research joint-ventures as institutional organizations designed to carry on collective research within selective coalitions can take place.

Signalling becomes relevant in this context as a device to reduce knowledge transaction costs. Patents are essential tools to signal the levels and the characteristics of the knowledge embodied in each organization.

A new chapter in the economics of intellectual property rights emerges here. Patents are no longer regarded only as tools to increase appropriability but also as devices to increase transparency in the knowledge markets and hence facilitate markets transactions. The build-up of reputation, by means of publications and scientific sociality also plays an important role as a signalling device within the scientific community (D avid and Keely, 2002).

The exclusivity of intellectual property rights is now questioned. The transition towards a system of interconnection rights, successfully experimented in telecommunication networks, seems more and morenecessary 
in the implementation of intellectual property rights. Perspective users of patents should find it easier to access the relevant property rights, provided that payments of royalties do take place. The shift towards the generalized use of compulsory licensing and of the liability rule, instead of the ex-ante agreement of the holders of intellectual property rights, might favour the systematic importance of technological externalities.

\section{Multiple equilibria, instability and the governance of common knowledge}

Technological knowledge can be understood as a collective good characterized by the complementarity, both between external and internal knowledgeand thestock of existing knowledgeand the flows of new knowledge. The aggregate outcomes of the governance mechanisms at the company level are far from being attracted by a single equilibrium point.

O nce again markets appear to provide a unique set for incentive mechanisms to work swiftly, the result of such market interactions however may or may not lead the system towards stable and fair solutions.

Therelationship between external and internal knowledgebecomesakey issue. It is immediately clear that substitutability cannot apply. Unconstrained complementarity however also appears inappropriate. The hypothesis of a constrained multiplicativerelationship can bearticulated. Theratio of internal to external knowledge seems relevant. N either can the companies generate new knowledgerelying only on external nor internal knowledge as an input. W ith an appropriate ratio of internal to external knowledge instead internal knowledge and external knowledgeinputsenter into a constrained multiplicative production function. Both below and above the threshold of the appropriate combination of the complementary inputs the company cannot achievethemaximum output. The amount of knowledge generated by each company depends upon the constrained multiplicative relationship between internal and external knowledge inputs. For any given amount of external knowledge available a given amount of internal knowledge inputs, and vice-versa for any given amount of internal knowledge, a given amount of external knowledge, is necessary in order to generate a maximum amount of knowledge output. 
The ratio of internal to external knowledge inputs plays a crucial role. This can be easily modelled as follows:

(1) $\mathrm{KY}=\mathrm{IK} * \mathrm{EK} * \mathrm{Z}$

(2) $Z=(I K / E K)$ for $\max Z=1$ when IK/EK $=X$

where YK is the knowledge output for each firm, EK and IK are respectively internal knowledge and external knowledge inputs. The actual value of $X$ dependsupon industrial, technological and historical circumstances.

An important result is now obtained. Because of the complementarity, between internal and external knowledge, especially if it is specified in terms of a constrained multiplicative relationship, the aggregate outcome of both market transactions and interactions are unstableand sensitiveto interactions and subjective decision-making. When both demand and supply schedules are influenced by externalities, multiple equilibria exist (M armolo, 1999; Autant-Bernard, 2001).

Theamount of knowledge each company can generate dependsupon the amount of external knowledge available, that is, upon theamount of knowledge that other companies, especially when involved in complementary research projects, have generated and cannot appropriate or arewilling to exchange. The amount of external knowledge availableat any point in timeand in regional and technological space depends upon the amount of technological knowledge generated and upon the conditions of technological communication within modules of complementary technological knowledge. The market provision of technological knowledgeispossible, provided appropriategovernancemechanisms are in place, but the levels are undetermined.

A new step along this line of enquiry can be made with the full appreciation of thelocalized character of technological knowledge and of the implications of thekey role played in this context by learning processes. The notion of localized technological knowledgein fact makes it possibleto stress the role of knowledge as a joint-product of the economic and production activity. Agents learn how, when, where and what, also and mainly, out of their experience, accumulated in daily routines. The introduction of new 
technologies is heavily constrained by the amount of competence and experience accumulated by means of learning processes in specific technical and contextual procedures (Antonelli, 1999). Agents, in this approach, can generate new knowledge, only in limited domains and fields where they have accumulated sufficient levels of competence and experience. 0 nce again a strict complementarity must be assumed between learning, as a knowledge input, and other knowledge inputs, either internal such as R\& D laboratories and external ones.

A very interesting case now emerges: in the markets for knowledge, both demand and supply externalities as well as joint-production apply and exert their effects. $0 \mathrm{n}$ the supply side, the amount of knowledge generated, dependsupon theinnovative behaviours of theagents as well as on the general production levels of the economic system at each point in time and in the relevant past, because of the role of learning. $0 \mathrm{n}$ the demand side, as it is well clear, network externalities among knowledge users exert a ubiquitous role. The position and the slope of the demand schedule depend on the position and the slope of the supply schedule and vice-versa. The latter in turn are influenced by the aggregate conditions of the economic system: learning rates depend upon theamount of output. N eedless to say however aggregate output is influenced by the amount of technological knowledge generated in the system, via the total factor productivity effects.

At each point in time any solution can be found, but such solution has not the standard characteristics of stability and replicability. In the markets for technological knowledge each equilibrium point is erratic. Little shocks, at the aggregate and disaggregated levels, can push the system far away from any given values. $\mathrm{N}$ o forces will act to push the system back towards the levels experienced in the previous phase. At the heart of the market system, the production and the distribution of technological knowledge, are characterized by multiple equilibria as well as micro-macro feedbacks and as such are sensitive to small and unintended shocks. M acroeconomic or monetary policies can havelong-lasting consequences if and when they affect thejoint-supply of experience and competenceand hencethey havean impact on the supply of technological knowledge. Thestrategic decision of companies to increase either the demand or the production of technological knowledge 
can also have long-lasting effects changing the parameters of the system. Entrepreneurial action hence may have here direct consequences at the economic system level changing the equilibrium conditions. Both failure and success however can be the result, depending on the outcomes of a chain of reactions which may take place.

Economic systems may be trapped in a low-knowledge-generation regime, while others remain in high-knowledge-generation ones. Path dependence, because of the role of learning and interdependence deploys here its powerful effects. Small events can push the system to oscillate from one regime to the other with long lasting consequences. In this context the issues of dynamic coordination among agentsand institutions becomes most relevant in order to assess the general outcome of each single action.

\section{Conclusion}

A long process has been taking place, since the old days of knowledge as a public good. A better understanding of the dynamics of knowledge accumulation has been elaborated. A ppropriability conditions seem now less relevant. D emand and network externalities play much a stronger role now. Transactions in the markets for knowledge do take place, al ong with systems of technological interaction based upon barter and reciprocity.

When increasing returns matter, such as in the case of technological externalities, and the price mechanism is unable to convey all the relevant information, the markets are unable to set the right incentives and hence move in the right direction. Governance mechanisms at the microeconomic level and economic policy at the system level are necessary in order to provide the necessary coordination.

A variety of governance mechanisms has been designed and implemented, or simply better understood. Companies and regions, by means of bureaucratic coordination and networking respectively can provide coordination according to the specific characteristics of knowledge.

The evolution of the intellectual property rights regime towards the separation between ownership and the exclusiveright of access to knowledge can provide important opportunities for the systematic val orization of both 
the markets for technology and the interactions among holders of complementary bits of knowledge. The mandated right of interconnection to bits of knowledge owned by third parties can take place with the implementation of the liability rule and the ex-post payment of royalties without the preliminary consensus of the patents holders.

Eventually however the need for economic policy seems stronger than ever. The governance of the markets for technological knowledge is not sufficient. M ultipleequilibria and micro-macro feedbacks affect the working of transactions and interactions in the markets for technological knowledge and their outcome. The dynamic coordination of agents plays in this context a central role.

The credible announcement of long lasting great initiatives and the implementation of large research projects based upon the framed and yet selective participation of a variety of agents in scientific and technological undertakings with direct economic and productive fall-outs should have the samepositive effects, often experienced for military expenses and related spatial ventures, also when applied in peaceful activities.

The governance of common knowledge needs to be implemented at the policy level.

\section{Bibliography}

Alchian, A.; D emsetz, H., "The Property Rights Paradigm", Journal of Economic History, v. 33, p. 16-27, 1973

Antonelli, C., The M icrodynamics of Technological Change, Routledge, London, 1999.

The M icroeconomics of Technological Systems, O xford: O xford U niversity Press, 2001.

The Economics of Innovation New Technologies and Structural Change, Routledge, London (forthcoming), 2003. 
; Ferrao, J. (eds.), Comunicação conhecimento colectivo e innovação. As vantangens da agglomeração geográfico, Lisbon: ICS, 2001.

; Q uéré, M ., The Governance of Interactive Learning within Innovation Systems, U rban Studies v. 39, (forthcoming), 2002.

Arora, A.; Fosfuri, A.; Gambardella, A., M arkets for Technology, C ambridge, M IT Press, 2001.

Argyres, N.S., "Technology Strategy Governance Structure and Interdivisional Coordination", Journal of Economic Behavior and Organization, v. 28, p. 337358, 1995.

; Liebeskind, J. P. "Privatizing the Intellectual Commons: Universities and the Commercialization of Biotechnology", Journal of Economic Behavior and Organization, v. 35, p. 427-454, 1998.

Autant-Bernard, C. , "Science and Knowledge Flows: Evidence from the French Case", Research Policy, v. 30, p.1069-1078, 2001.

Carroll, G.R.; Teece, D.J., Firms M arkets and H ierachies. The Transaction Cost Economics Prospective, O xford: O xford U niversity Press, 1999.

Cooper, D .P., "Innovation and Reciprocal Externalities: Information T transmission via Job M obility", Journal of Economic Behavior and Organization, v. 45, p. 403-425, 2001.

Cowan, R.; Jonard, N. (2002), The Working of Scientific Communities, in Geuna, A.; Salter, A.; Steinmueller, W.E. (eds.) Science and innovation. Rethinking the rationales for funding and governance, Aldershot: Elgar, 2002.

; David, P. A.; Foray, D., "The Explicit Economics of Knowledge Codification and Tacitness", Industrial and Corporate Change, v. 9, p. 211253, 2000.

D avid, P. A., "From M arket M agic to Calypso Science Policy. A Review of Terence Kealey's 'T he Economic Laws of Scientific Research'", Research Policy, v. 26, p. 229-255, 1997.

; Keely, L.C., "The Economics of Scientific Research Coalitions: Collaborative $\mathrm{N}$ etwork Formation in the Presence of $\mathrm{M}$ ultiple Funding Agencies, in Geuna, A.; Salter, A.; Steinmueller, W.E. (eds.) Science and Innovation. Rethinking the Rationales for Funding and Governance, Aldershot: Elgar, 2002.

Furubotn, E.G., "The N ew Institutional Economics and the Theory of the Firm", Journal of Economic Behavior and Organization, v. 45, p. 133-153, 2001. 
Kingston, W., "Innovation N eeds Patents Reforms", Research Policy, v. 30, p. 403423, 2001.

Langlois, R., Economics as a Process: Essays in the $\mathrm{N}$ ew Institutional Economics, Cambridge: Cambridge University Press, 1986.

Loasby, B.J., Knowledge Institutions and Evolution in Economics, London: Routledge, 1999.

Marmolo, E. (1999), "A Constitutional Theory of Public Goods", Journal of Economic Behavior and Organization, v. 38, p. 27-42, 1999.

M azzoleni, R. and Nelson, R.R., "The Benefits and the Costs of Strong Patent Protection: A Contribution to the Current D ebate", Research Policy, v. 27, p. 273-284, 1998.

M enard, C. (ed.), Institutions Contracts and Organizations. Perspectives from $\mathrm{N}$ ew Institutional Economics, Aldershot: Elgar, 2000.

Nelson, R.R.; Sampat, B.N., "M aking Sense of Institutions as a Factor Shaping Economic Performance", Journal of Economic Behavior and Organization, $v$. 44, p. 31-54, 2001.

N ooteboom, B., Learning and Innovation in O rganizations and Economics, O xford: Oxford University Press, 2000.

Penrose, E.T., T heT heory of the G rowth of the Firm, O xford: Basil Blackwell, 1959.

Swann, G.M .P., "W hen is Public Finance Preferable to Attainable Club Good Solutions?", in Geuna, A.; Salter, A.; Steinmueller, W.E. (eds.), Science and innovation. Rethinking the Rationales for Funding and Governance, Aldershot: Elgar, 2002.

Teece, D .J ., M anaging Intellectual Capital, O xford: O xford U niversity Press, 2000. Williamson, 0 .J., "The Economic Institutions of Capitalism", N ew York, Free Press, 1985. , The M echanisms of G overnance, O xford: O xford U niversity Press, 1996. 